\title{
Comparative Study between Unilateral Spinal Anesthesia Versus Ultrasound Combined Femoro-Sciatic Nerve Block for Lower Limb Surgery
}

\author{
SHIMAA S. AWAD, M.Sc.; AHMED M. SABER, M.D.; ASHRAF E. ELZEFTAWI, M.D. and \\ RABAB M. MOHAMED, M.D. \\ The Department of Anesthesiology, Surgical Intensive Care and Pain Medicine, Faculty of Medicine, Tanta University
}

\begin{abstract}
Background: The advantages of Unilateral Spinal Anesthesia (ULSA) over bilateral spinal anesthesia are less doses, cardiovascular side effects, and hospitalization. Femoral/Sciatic Nerve Block (FSNB) may decrease post-operative pain, nausea and vomiting, length of stay, surgical stress, morbidity and mortality and may improve mobilization and recovery of gastrointestinal function.
\end{abstract}

Aim of Study: The aim of this study is to compare ULSA versus FSNB by Ultrasound (US) guided as anesthetic technique for cases undergoing elective lower limb surgery.

Material and Methods: This prospective randomized study was carried out on 60 adult educated patients, aged 18:60, of both sex, ASA I-II and scheduled for lower limb surgery at Tanta University Hospitals. Patients were randomized into 2 equal groups (30 patients in each); Group-I: ULSA and GroupII: US guided FSNB. Mean Arterial Blood Pressure (MAP) and Heart Rate (HR) were recorded before block and every $15 \mathrm{~min}$ intraoperative and at $30,60 \mathrm{~min}, 2,3,4,6$ and $12 \mathrm{~h}$ post-operative. Onset and duration of both sensory and motor block, the first time for need of rescue analgesia (morphine) and Visual Analogue Scale (VAS) at rest and with activity (at $0,1,2,3,4,6$ and $12 \mathrm{hr}$ ) were recorded. Patient and surgeon satisfaction and any post-operative side effect were recorded.

Results: Onset of sensory and motor block was significantly shorter in ULSA, but the duration of sensory and motor block was prolonged in FSNB with delayed first dose of analgesic. Intraoperative HR and MAP showed insignificant difference and post-operative significant increase in ULSA. VAS at activity showed earlier need for rescue analgesic in ULSA. There was no significant difference in surgeon and patient satisfaction with minimal side effects.

Conclusion: Both ULSA with $2 \mathrm{ml}$ heavy bupivacaine $0.5 \%$ given slowly over one minute and US guided FSNB using combination of $0.25 \%$ bupivacaine and $1 \%$ lidocaine resulted in comparable adequate intraoperative anesthesia, stable hemodynamics and adequate surgeon and patient satisfaction with minimal side effects. US guided FSNB was superior to ULSA in post-operative analgesia.

Correspondence to: Dr. Shimaa S. Awad, The Department of Anesthesiology, Surgical Intensive Care and Pain Medicine, Faculty of Medicine, Tanta University
Key Words: Unilateral spinal anesthesia-Femoro-sciatic nerve block - Lower limb surgery.

\section{Introduction}

REGIONAL anesthesia techniques are used as an alternative to general anesthesia because both peripheral nerve blocks and spinal anesthesia provide sufficient anesthesia, better post-operative analgesia and higher patient satisfaction than general anesthesia, in addition to being minimally invasive using less resources, and it reduces the pulmonary aspiration of gastric content which is one of the most feared complications of general anesthesia $[\mathbf{1}, \mathbf{2}]$.

The advantages of unilateral spinal anesthesia over bilateral spinal anesthesia are low cardiovascular side effects, strong blockade during surgery using low doses, fewer hospitalization; and the disadvantage is that it requires protecting the lateral position for a while [3-5]

Patient may have concomitant diseases that compromise cardiovascular and pulmonary function and spinal stability. The uncompensated hemodynamic response to SA-induced physiologic changes resulting from severely decreased cardiac function, the antiplatelet and anticoagulant therapy make SA inappropriate to surgical anesthesia [6]. These factors even prevent general anesthesia practices from being conducted [7]. With the presence of these factors, alternative anesthetic techniques are needed such as femoral/sciatic nerve block [8]

Ultrasound guidance may improve the punctureto-onset interval and the quality of sensory block in all nerves while avoiding complications, less local anesthetic is required because it is applied more accurately with ultrasound guidance [9]. 
The aim of this study is to compare unilateral spinal anesthesia versus femoral/sciatic nerve block by ultrasound guided as anesthetic technique for cases undergoing elective lower limb surgery.

\section{Material and Methods}

This prospective randomized study was carried out on 60 adult educated patients, aged between 18:60, of both sex with physical status ASA I-II scheduled for lower limb surgery at Tanta University Hospitals.

The study was from January 2018 to December 2018 after approval from Institutional Ethics Committee and informed consent from each patient. All data of patients were confidential with secret codes and private file for each patient, all given data were used for the current medical research only. Any unexpected risks encountered during the course of the research were cleared to the participants as well as to the Ethical Committee on time. Every patient received an explanation to the purpose of the study and had secret code number to ensure privacy to participants and confidentiality of data.

Exclusion criteria were: Patient refusal, uncooperative patient, unconscious patients, cases with head trauma, history of relevant drug allergy to local anesthetics, local infection at the site of the block, patients with coagulopathies and impaired platelet functions, patients with hemodynamic instability, previous neurological deficit in lower limb and previous femoral artery grafts or injuries.

\section{Pre-anesthetic management:}

Pre-operative assessment was done by history taking, clinical examination and routine laboratory investigation (complete blood picture, PT, PTT).

VAS scale illustrated to all patient clearly to insure accurate expression of post-operative pain severity by making a line of $10 \mathrm{~cm}$ length graded from 0 to 10 and demonstrating how to detect pain severity, $0=$ no pain, and $10=$ most severe pain.

\section{Monitoring:}

In the operating room, after an intravenous line was established with 18-gauge cannula, all patients were attached to a monitor which display the following parameters ECG, heart rate, non-invasive blood pressure and $\mathrm{O}_{2}$ saturation, all the base line parameters were observed and recorded. The patients were given oxygen at the rate of $2 \mathrm{~L} / \mathrm{min}$ through a nasal canula. All patients received $1 \mathrm{mg}$ midazolam and $50 \mu \mathrm{g}$ fentanyl intravenously $5 \mathrm{~min}$ before the start. An intravenous preload of $500 \mathrm{~mL}$ of Ringer's lactate was given.

\section{Patients allocation:}

This study included 60 patients; they were randomly classified with computer by using closed envelope into two equal groups, each group contains 30 patients; Group-I: Unilateral Spinal Anesthesia (ULSA) group and Group-II: Ultrasound guided Femoral/Sciatic Nerve Block (FSNB) group.

\section{ULSA Group:}

ULSA was performed with the patient in sitting position, in which the patient sits on the edge of the operating table with legs on chair, leaning forward arching his back.

After complete aseptic technique, iliac crest was palpated, and thumb extended to meet the midline, feeling the space between L3-4 or L4-5, then subcutaneous injection of $1: 2 \mathrm{ml} 1 \%$ lidocaine was administered, next, a 22-gauge spinal needle was introduced, after confirmation of correct placement of the spinal needle by free flow of Cerebrospinal Fluid (CSF), $2 \mathrm{ml}$ of $0.5 \%$ hyperbaric bupivacaine was slowly injected over one minute without any aspiration, then spinal needle was withdrawn. After withdrawal of the spinal needle, the patient was placed in the lateral decubitus position on the side of operating limb for $20 \mathrm{~min}$, then motor, sensory and sympathetic functions were evaluated, assessment was done immediately after spinal injection and at 5 minutes interval for 20 minutes and every 15 minutes until end of surgery and regression of block to L2 level. Sensory block was assessed as complete loss of sensation to pinprick (via a 23-gauge hypodermic needle). Motor block was assessed using a modified Bromage scale 10 . Patients were judged ready for surgery when complete loss of pinprick sensation was reported at T12 on the operative limb. Sensory testing was done from caudal to cephalad and analgesic level was defined as the cephalad most dermatome at which the patient had decreased sharp sensation. The spinal anesthesia was termed as unilateral when the sensory block was up to or above T12 level and modified Bromage score for motor block was $>2$ on the operative limb and no detectable sensory and motor block on the other limb. If any sensory or motor block appeared on other side, the block was not defined as unilateral spinal block and patient was excluded from the study. Surgery commenced after adequate sensory block was reached at $\mathrm{T} 12$.

Patients in (Group-II): Ultrasound guided Femoral \& Sciatic Nerve Block (FSNB):

The operator stands on the side that was to be blocked, facing the patient with the ultrasound 
machine across the other side of the patient. The patient was in the supine position, with the table flattened to maximize operator access to the inguinal area.

\section{Femoral nerve block:}

With the patient was in the proper position for blocking femoral nerve, the skin was sterilized by $2 \%$ povidone-iodine, gel was put on the doppler curved probe and then the probe put in sterile sheath, the wide band transducer $5-10 \mathrm{MHz}$ (SonoScape ${ }^{\circledR}$, SSI-6000, China) was placed on the inguinal region to allow visibility of the femoral artery and vein, the nerve was seen in cross section as a hyper echoic speckled triangular or oval shaped structure just lateral to the artery. Tilt and rotation were required to optimize the view of this nerve. compression was used to help differentiate arteries and veins. Finally, color doppler imaging was associated with real-time ultrasonography in all cases. A skin wheal of lidocaine $1 \% 2-3 \mathrm{ml}$ was made on the lateral aspect of the thigh $1 \mathrm{~cm}$ away from the lateral edge of the transducer. A 22-gauge, $150-\mathrm{mm}$ insulated b-bevel needle (Stimuplex; BBraun, Boulogne-Billancourt, France) was inserted in-plane in a lateral-to-medial orientation and advanced toward the femoral nerve. It was introduced longitudinally to the ultrasound beam (inplane technique) until the site of the nerve. When the needle tip had crossed fascia lata and fascia iliaca and into the femoral nerve compartment, aspiration was attempted with the syringe to check blood to ensure against accidental vascular puncture. Once positioning was confirmed by imaging, injection of $20 \mathrm{ml}$ of $0.25 \%$ Bupivacaine and $10 \mathrm{ml}$ of $1 \%$ lidocaine was performed in boluses of $5 \mathrm{ml}$ after aspiration to guard against intravascular injection and any resistance or pain on injection necessitated repositioning of the needle to avoid intraneural injection.

\section{Sciatic nerve block (anterior approach):}

With the patients on the same position, the hip was abducted, externally rotated, and the knee flexed until exposure of the calf and foot. The doppler curved probe was placed perpendicular to skin approximately $8 \mathrm{~cm}$ distal to the inguinal crease to identify the sciatic nerve. The sciatic nerve was visualized posterior and medial to the lesser trochanter of the femur. Finally, color doppler imaging was associated with real-time ultrasonography in all cases. Then subcutaneous anesthesia was done at the puncture site with lidocaine $1 \% 2 \mathrm{ml}$. A 22 gauge, $150-\mathrm{mm}$ insulated b-bevel needle (Stimuplex; B-Braun, Boulogne-Billancourt, France) was inserted and directed from anteromedial to poste- rolateral aspect of the thigh. Then, aspiration was attempted with the syringe to check blood to ensure against accidental vascular puncture. Once positioning was confirmed by imaging, injection of $15 \mathrm{ml}$ of $0.25 \%$ Bupivacaine and $10 \mathrm{ml}$ of $1 \%$ lidocaine was performed in boluses of $5 \mathrm{ml}$ after aspiration to guard against intravascular injection and any resistance or pain on injection necessitated repositioning of the needle to avoid intraneural injection.

Sensory block was assessed as loss of pinprick sensation to a 22-gauge needle for both femoral and sciatic distributions.

Adequate femoral nerve block was defined as complete inability to elevate the foot of the operated limb from the operating table.

For sciatic nerve, motor blockade was evaluated simultaneously for the two main branches of the sciatic nerve, the common peroneal and tibial nerves (dorsiflexion and plantar flexion of the foot against manual resistance respectively).

Fluid therapy included maintenance plus deficit fluids (maintenance $\mathrm{X}$ fasting hours) and third space losses $(4 \mathrm{ml} / \mathrm{kg} / \mathrm{h})$ used ringer solutions in both groups.

If needed, we used midazolam first for tactile discomfort during surgery at incremental doses with $1 \mathrm{mg}$, and to attenuate pain, $50 \mu \mathrm{g}$ fentanyl was available to be administered alternatively as needed. The total amount of intra operative sedation and analgesia were calculated.

At the end of the surgery, the patient was then transported to the Post Anesthesia Care Unit (PACU) for $2 \mathrm{~h}$ and then transferred to the ward for $24 \mathrm{~h}$.

Morphine was prescribed for postoperative pain control (1-2mg IV if VAS > 4) during the first 24h post-operatively.

\section{Measurements:}

Demographic data (age, gender, BMI and ASA classification), type and duration of surgery. Mean Arterial Blood Pressure (MAP) and Heart Rate (HR) had been recorded before block and every $15 \mathrm{~min}$ intra operative and for $12 \mathrm{~h}$ post-operative at $30 \mathrm{~min}, 60 \mathrm{~min}, 2 \mathrm{hr}, 3 \mathrm{hr}, 4 \mathrm{hr}, 6 \mathrm{hr}$ and $12 \mathrm{hr}$.

Onset of sensory block (the time from the end of the injection till loss of response to painful stimuli), onset of motor block (the time from end of injection till the loss of motor power to Grade 3 of modified Bromage scale), duration of sensory 
block (the time from the onset of sensory block till the time of the first requirement of analgesia by using Visual Analogue Pain Scale [when VAS >4] [11]), duration of motor block (the time from the onset of motor block till the return of motor power to grade 0 by using the modified Bromage scale) and the first time for need of rescue analgesia (morphine) and total amount of doses of rescue analgesia were recorded. VAS had been done at rest and with activity (movement in bed) at 0,1 , 2, 3, 4, 6 and $12 \mathrm{hr}$.

Patient and surgeon satisfaction by a four-point verbal rating scale $(1=$ extremely unsatisfied, $2=$ unsatisfied, $3=$ satisfied, and $4=$ extremely satisfied) and any undesirable post-operative side effect or complications were recorded.

The primary outcome is the time to first for request for rescue analgesia and the secondary outcomes are visual analogue scale, total amount of morphine consumption and side effects.

\section{Sample size and statistical analysis:}

It was found that the number of 27 patient was needed to have a significant difference between the two groups as regard to duration of sensory analgesia with a significant difference based on the time of first rescue analgesia as the primary end point between the two groups based on the following criteria: $95 \%$ confidence limit, $80 \%$ power of the study and Group I:II ratio 1:1.

The collected data were organized, tabulated and statistically analyzed using SPSS (IBM, USA) Version 25. For quantitative data, mean and standard deviation were calculated and comparison was done by student $t$-test. For qualitative data, frequency and percentage were calculated and comparison between two groups was done using Chisquare test $\left(\mathrm{X}^{2}\right)$. The level of significance was adopted at $p$-value $<0.05$.

\section{Results}

Eighty patients were recruited for the study and twenty patients were excluded. Sixty patients were randomly allocated into two equal groups; $30 \mathrm{pa}-$ tients received ULSA (Group 1), while 30 patients received US guided FSNB (Group 2) Fig. (1).

Table (1): Modified Bromage scale.

\begin{tabular}{ll}
\hline 0 & No motor block \\
1 & Can flex knee, move foot, but cannot raise leg \\
2 & Can move foot only \\
3 & Cannot move foot or knee \\
\hline
\end{tabular}

\section{Allocated to Group $1(n=30)$ \\ - Received unilateral spinal technique by injecting intrabecal local anesthetic of $10 \mathrm{mg}(2 \mathrm{ml})$ of hyperbaric bupivacaine $0.5 \%$ on lateral position.}

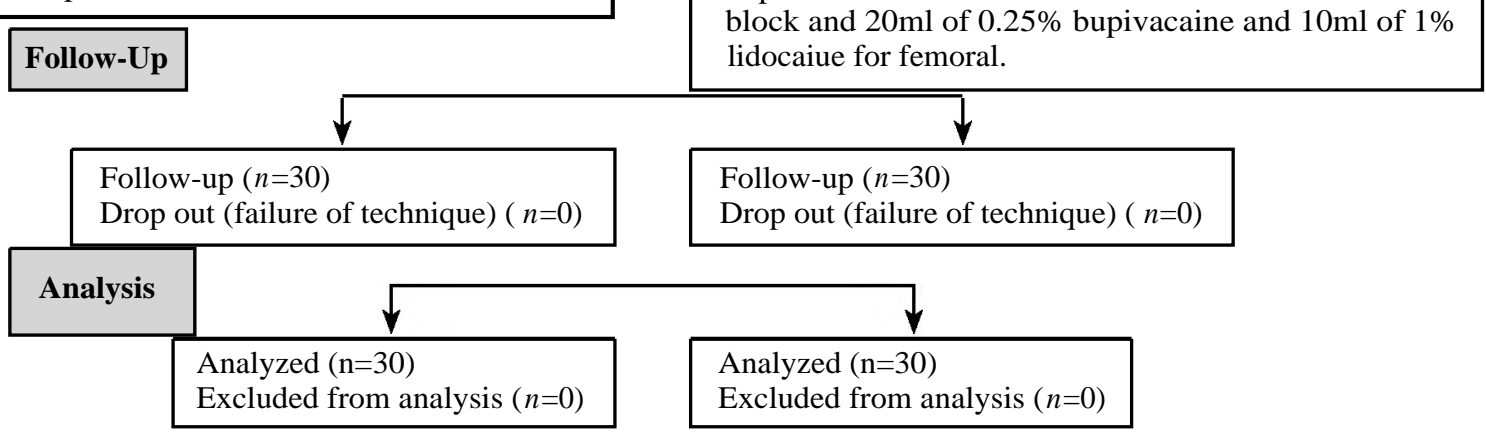

Fig. (1): Patient flow up through the study.
Allocated to Group $2(n=30)$

- Received femoral/sciatic nerve block by ultrasound and nerve stimulutor technique by injecting $15 \mathrm{ml}$ of $0.25 \%$ bupivacaiue and $10 \mathrm{ml}$ of $1 \%$ lidocaiue for sciatic nerve block and $20 \mathrm{ml}$ of $0.25 \%$ bupivacaine and $10 \mathrm{ml}$ of $1 \%$ lidocaiue for femoral.

Follow-up $(n=30)$

Drop out (failure of technique) $(n=0)$

Analyzed $(\mathrm{n}=30)$

Excluded from analysis $(n=0)$ 
Comparison between the two groups showed insignificant difference as regards age, BMI, gender, ASA physical status and duration of surgery (Table 2).

Table (2): Demographic characteristics comparison between both groups.

\begin{tabular}{|c|c|c|c|}
\hline Demographic characteristics & $\begin{array}{l}\text { Group } 1 \\
(\mathrm{n}=30)\end{array}$ & $\begin{array}{l}\text { Group } 2 \\
(\mathrm{n}=30)\end{array}$ & $\begin{array}{c}p- \\
\text { value }\end{array}$ \\
\hline $\begin{array}{l}\text { Age }(y): \\
\quad(\text { Mean } \pm \mathrm{SD})\end{array}$ & $32.8 \pm 6.66$ & $35.3 \pm 6.40$ & 0.155 \\
\hline $\begin{array}{l}B M I(\mathrm{~kg} / \mathrm{m} 2): \\
\quad(\text { Mean } \pm \mathrm{SD})\end{array}$ & $23.88 \pm 0.16$ & $23.68 \pm 0.17$ & 0.069 \\
\hline $\begin{array}{l}\text { Gender: } \\
\text { Male } \\
\text { Female }\end{array}$ & $\begin{array}{l}16(56.5 \%) \\
14(43.3 \%)\end{array}$ & $\begin{array}{l}13(45.6 \%) \\
17(53.3 \%)\end{array}$ & 0.6054 \\
\hline $\begin{array}{l}\text { ASA classification: } \\
\text { I } \\
\text { II }\end{array}$ & $\begin{array}{l}20(66.6 \%) \\
10(33.3 \%)\end{array}$ & $\begin{array}{l}18(60 \%) \\
12(40 \%)\end{array}$ & 0.788 \\
\hline $\begin{array}{l}\text { Type of operations: } \\
\text { Knee arthroscope } \\
\text { Endovenous ablation } \\
\text { Below knee amputation }\end{array}$ & $\begin{array}{ll}15 & (50 \%) \\
8 & (26.7 \%) \\
7 & (23.3 \%)\end{array}$ & $\begin{array}{l}13(43.3 \%) \\
11(36.7 \%) \\
6 \quad(20 \%)\end{array}$ & 0.856 \\
\hline $\begin{array}{l}\text { Duration of surgery }(\text { min }) \text { : } \\
\quad(\text { Mean } \pm \mathrm{SD})\end{array}$ & $83.3 \pm 9.19$ & $84.8 \pm 8.76$ & 0.518 \\
\hline
\end{tabular}

Onset of sensory and motor block were shorter in ULSA technique than in FSNB technique, but the duration of sensory and motor block were prolonged in FSNB technique than in ULSA technique. The first dose of IV analgesic was earlier in ULSA technique than in FSNB technique (Tables 3,4).

Table (3): Comparison between both group regarding onset and duration of both sensory block and motor block.

\begin{tabular}{|c|c|c|c|}
\hline & $\begin{array}{c}\text { Group } 1 \\
\text { Mean } \pm \text { SD }\end{array}$ & $\begin{array}{c}\text { Group } 2 \\
\text { Mean } \pm \text { SD }\end{array}$ & $\begin{array}{c}p- \\
\text { value }\end{array}$ \\
\hline $\begin{array}{l}\text { - Onset of sensory } \\
\text { block (min) }\end{array}$ & $4.8 \pm 1.6$ & $17.2 \pm 2.65$ & $<0.001 *$ \\
\hline $\begin{array}{l}\text { - Onset of motor } \\
\text { block (min) }\end{array}$ & $8.03 \pm 1.7$ & $23.86 \pm 4.56$ & $<0.001 *$ \\
\hline $\begin{array}{l}\text { - Duration of motor } \\
\text { block (min) }\end{array}$ & $145.66 \pm 19.26$ & $245.33 \pm 6.69$ & $<0.001 *$ \\
\hline $\begin{array}{l}\text { - Duration of sensory } \\
\text { block (min) }\end{array}$ & $130.66 \pm 13.39$ & $230.33 \pm 7.52$ & $<0.001 *$ \\
\hline
\end{tabular}

Table (4): First rescue analgesia (min) and total analgesic requirement $(\mathrm{mg})$ of both groups.

\begin{tabular}{lccc}
\hline & $\begin{array}{c}\text { Group I } \\
\text { Mean } \pm \text { SD }\end{array}$ & $\begin{array}{c}\text { Group II } \\
\text { Mean } \pm \text { SD }\end{array}$ & $\begin{array}{c}p \text { - } \\
\text { value }\end{array}$ \\
\hline - First rescue analgesia & $167.63 \pm 16.08$ & $253.33 \pm 9.09$ & $<0.001^{*}$ \\
$\begin{array}{l}\text { - Tin) } \\
\text { Total analgesic } \\
\text { requirement (mg) }\end{array}$ & $10.1 \pm 1.62$ & $4.9 \pm 1.58$ & $<0.001^{*}$ \\
\hline
\end{tabular}

Intraoperative HR and MAP; both showed insignificant difference in both group and postoperative significant difference Figs. (2-5).

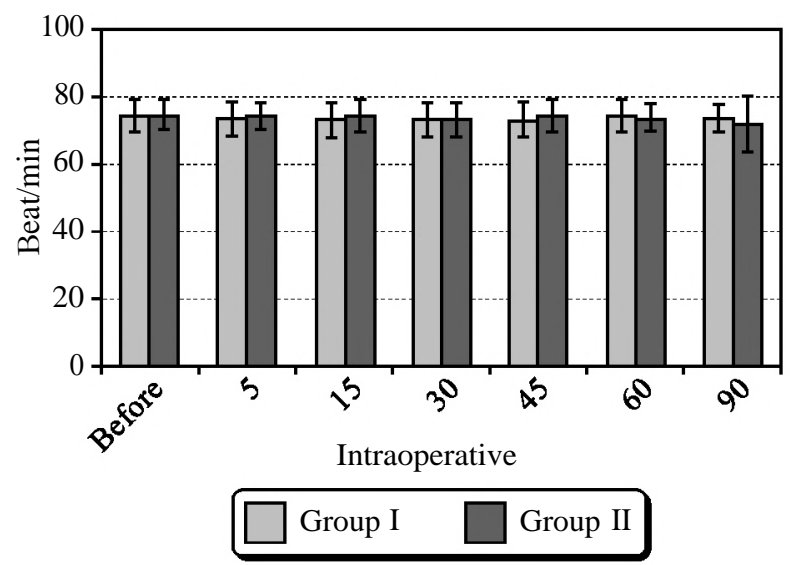

Fig. (2): Intraoperative HR in both groups.
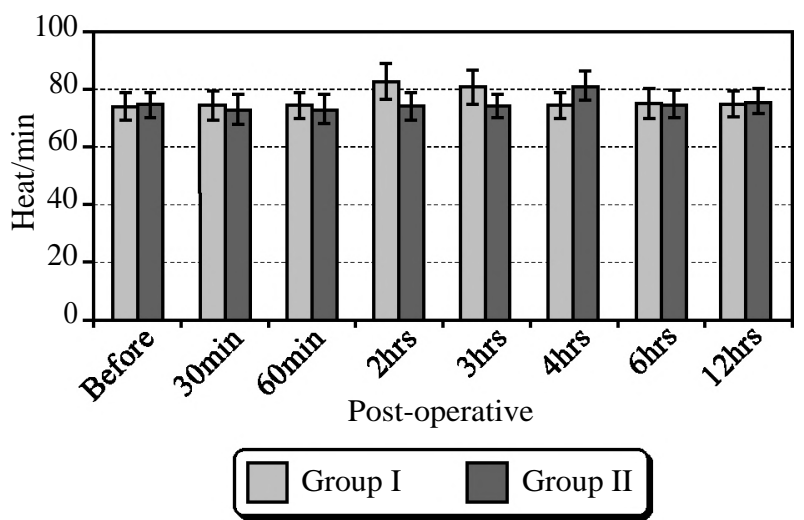

Fig. (3): Post-operative HR in both groups.

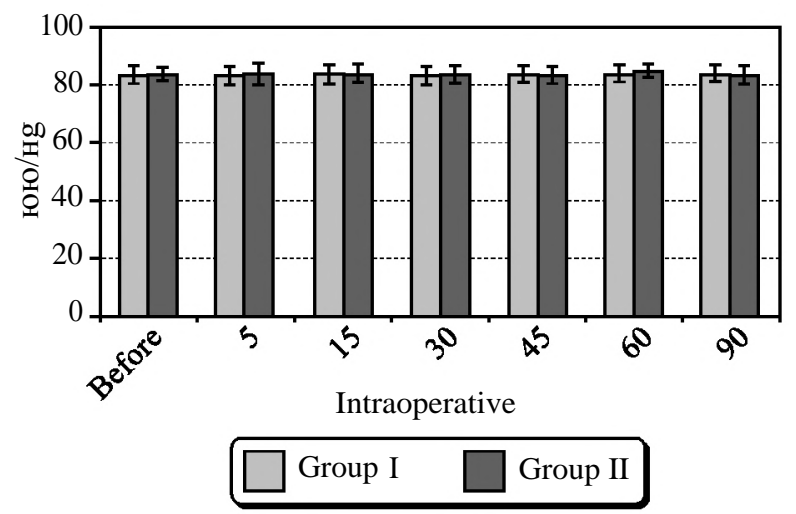

Fig. (4): Intraoperative MAP in both groups.

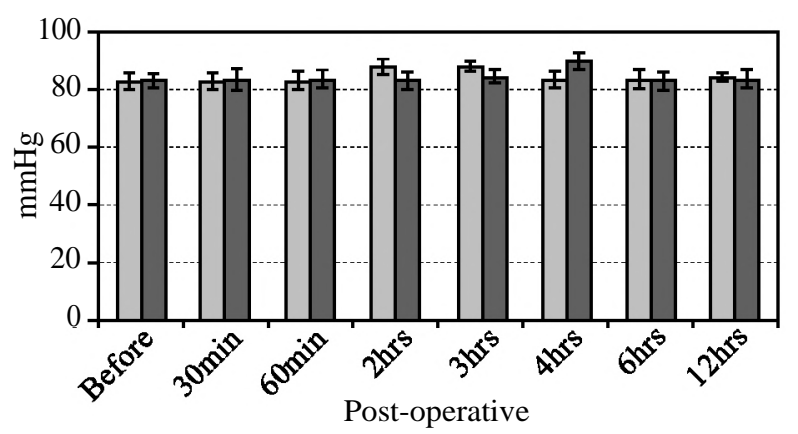

Group I $\square$ Group II

Fig. (5): Post-operative MAP both in groups. 
For VAS at activity showed earlier need for rescue analgesic in ULSA group than in FSNB group (Table 5).

No difference was noted between two groups as regards surgeon and patient satisfaction. The two techniques were associated with minimal side effects and complications (Table 6).

Table (5): Visual Analogue Score (VAS) at rest and at activity in both groups.

\begin{tabular}{|c|c|c|c|c|c|c|c|}
\hline & 0 & $1 \mathrm{~h}$ & $2 \mathrm{~h}$ & $3 h$ & $4 \mathrm{~h}$ & $6 \mathrm{~h}$ & $12 \mathrm{~h}$ \\
\hline \multicolumn{8}{|l|}{ VAS at rest: } \\
\hline Median & 1 & 1 & 1 & 2 & 1 & 1 & 1 \\
\hline Range & $0-1$ & $0-1$ & $0-1$ & $2-3$ & $1-2$ & $0-1$ & $1-2$ \\
\hline \multicolumn{8}{|l|}{ - Group II: } \\
\hline Median & 1 & 1 & 1 & 1 & 1.5 & 1 & 1 \\
\hline Range & $0-2$ & $0-1$ & $0-1$ & $0-1$ & $1-2$ & $0-1$ & $0-2$ \\
\hline$p$-value & 0.023 & 0.021 & 0.987 & $<0.001^{*}$ & 0.798 & 0.409 & $0.010^{*}$ \\
\hline \multicolumn{8}{|l|}{$\begin{array}{l}\text { VAS at } \\
\text { activity: }\end{array}$} \\
\hline Median & 2 & 2 & 3 & 2 & 2 & 2 & 2 \\
\hline Range & $0-3$ & $1-3$ & $2-4$ & $1-3$ & $1-3$ & $0-3$ & $2-3$ \\
\hline \multicolumn{8}{|l|}{ - Group II: } \\
\hline Median & 2 & 2 & 2 & 2.5 & 2 & 2 & 2 \\
\hline Range & $0-3$ & $1-3$ & $1-4$ & $2-4$ & $0-3$ & $0-3$ & $1-3$ \\
\hline$p$-value & 0.761 & 0.215 & $<0.001 *$ & $0.028 *$ & 0.738 & 0.955 & 0.073 \\
\hline
\end{tabular}

Table (6): Patient and surgeon satisfaction and complications in both groups.

\begin{tabular}{lccc}
\hline & $\begin{array}{c}\text { Group I } \\
(\mathrm{n}=30)\end{array}$ & $\begin{array}{c}\text { Group II } \\
(\mathrm{n}=30)\end{array}$ & $\begin{array}{c}p^{-} \\
\text {value }\end{array}$ \\
\hline Patient satisfaction: & & & \\
$\quad$ Extremely satisfied & 16 & 14 & 0.689 \\
$\quad$ Satisfied & 13 & 10 & \\
Unsatisfied & 1 & 1 & \\
Extremely unsatisfied & 0 & 0 & \\
Surgeon satisfaction: & & & \\
$\quad$ Extremely satisfied & 20 & 19 & 0.709 \\
Satisfied & 8 & 10 & \\
Unsatisfied & 2 & 1 & \\
Extremely unsatisfied & 0 & 0 & \\
Complications and side effects: & & & \\
Hypotension & 2 & 0 & 0.313 \\
Bradycardia & 1 & 0 & 0.15 \\
Nausea and vomiting & 2 & 1 & 0.35 \\
Pruritis & 0 & 0 & \\
Excessive sedation & 0 & 0 & \\
Headache & 1 & 0 & 0.121 \\
Paresthesia & 1 & 4 & 0.35 \\
Intravascular injection & 0 & 0 & \\
\hline
\end{tabular}

\section{Discussion}

ULSA is a promising alternative to traditional, widely used technique of central neuraxial blocks, as it markedly restricts the anesthetized area, thereby, decreasing the risk of adverse events and complications. Spinal anesthesia is a less preferred technique or even contraindicated in patients with moderate to severe heart failure [12]

Patient may have concomitant diseases that compromise cardiovascular and pulmonary function and spinal stability. The uncompensated hemodynamic response to SA-induced physiologic changes resulting from severely decreased cardiac function [6]. These factors even prevent general anesthesia practices from being conducted and femoral/sciatic nerve block may be a good alternative [8].

In this study, the mean duration of procedure in Group I was shorter than in Group II. The duration of preparation for the surgery included the duration of lateral lying which was a waiting period for the effect of the unilateral spinal anesthesia. The lateral waiting duration was 20 minutes in this study.

Although the time of administration of FSNB was longer than the time of administration of spinal anesthesia, the duration of preparation for surgery was similar in both procedures [2]

The patient's position during and immediately after spinal anesthesia influences the spinal distribution of drugs. If anesthetic drug solution is hypoor hyperbaric with respect to the cerebrospinal fluid, it is possible to create a unilateral block. Moreover, the distance between the left and right nerve roots in the lumbar and thoracic regions is about $10-15 \mathrm{~cm}$, which makes it possible to achieve unilateral spinal anesthesia [13]. In this study, 10 patients were excluded as they developed bilateral spinal anesthesia.

In agreement with the this study, Tekye and Alipour [14] who injected $1.5 \mathrm{ml}$ of hyperbaric bupivacaine $0.5 \%$ and the patient was kept in the lateral position for 20min which led to ULSA in $94.45 \%$ of cases. In two cases, the anesthetic drug spread to the other side, resulting in bilateral spinal anesthesia.

As regard HR and MAP, the present study found that it was insignificant when both groups were compared to each other. There was hemodynamics stability as none of the patients developed hypotension or bradycardia. This could be explained by the preload of $500 \mathrm{ml}$ of ringer solution and the restriction of the block to one side in Group I and in Group II, there was no sympathetic or autonomic block.

In agreement with this study, Tummala $\mathrm{V}$ [15], studied on high-risk geriatric patients for surgeries around the hip joint patients. To reduce the inci- 
dence and severity of hypotension, a unilateral spinal technique has been described in which low dose intrathecal local anesthetic was used in an attempt to reduce hypotension. The onset of block was not delayed by this method, but at the same time adequate level of sensory block was obtained. The ULSA was particularly advantageous in highrisk geriatric patients to reduce hemodynamic side effects. The results indicated that unilateral spinal technique was effective and safe, produced stable hemodynamic and provision of prolonging analgesia with low dose intrathecal local anesthetic as compared to spinal anesthesia in geriatric patients undergoing major surgeries involving the hip joint.

Also in agreement with this study, Chohan, et al., [16] administered unilateral spinal anesthesia prior to lower-limb surgery in elderly patients with ASA classification of III or IV. The authors found no significant hemodynamic changes. They used hyperbaric bupivacaine $0.5 \%$ (1.1-1.8mL).

Additionally, Glaser et al., [17] compared 3.5ml of isobaric levobupivacaine to $3.5 \mathrm{ml}$ of isobaric bupivacaine in patients scheduled for elective hip replacement and found those equally effective with no intergroup difference in hemodynamic characteristics.

Also in agreement Akkaya et al., [18] compared ultrasound guided femoral and sciatic nerve block and spinal anesthesia for total knee arthroplasty and found peripheral nerve block a simple, safe, and effective method. Patients who were not candidates for safe spinal or general anesthesia because of cardiovascular instability can undergo lower extremity surgery under combined femoral and sciatic nerve block safely.

Similarly, Tantry et al., [19] conducted a study in anticoagulated patients with the severe valvular disease under combined femoral and sciatic nerve block without any complications.

As regard the onset of sensory and motor block, this study found that it was significantly shorter in Group I when compared to Group II.

As regard to duration of sensory and motor block. In the present study there were significant difference between two groups. There was rapid recovery of sensory and motor block in Group I.

In agreement with this study, Fanelli et al., [20] compared unilateral and conventional bilateral bupivacaine spinal block in outpatients undergoing knee arthroscopy. In the unilateral group, they used $8 \mathrm{mg}$ of hyperbaric bupivacaine $0.5 \%$ in 50 patients in lateral decubitus position after spinal injection whome maintained in the lateral position for 15 minutes. They found that, for the unilateral group, sensory and motor blocks on the operated limb were T9 (T12-T2) with a Bromage score 0/1/2/3 in $0 / 2 / 3 / 45$ patients, respectively, in the unilateral group.

In another study, Valanne et al., [21] compared the effect of $4 \mathrm{mg}$ and $6 \mathrm{mg}$ of hyperbaric bupivacaine for ULSA in 106 ambulatory adult patients undergoing knee arthroscopy and found that both doses produced efficient and adequate sensory and motor block. However, rapid regaining of motor function was reported with the lower dose.

This study results are comparable with studies by V. Chakravarthy et al., [22] and Fournier et al., [23] reported the same duration of sensory and motor block after combined sciatic and femoral 3in-1 block.

Also on agreement with our study, V. Chakravarthy et al., [22] reported that motor block regression time was the same as in this study.

Also on agreement with these results, Sansone $\mathrm{V}$ [24] studied patients scheduled for knee arthroscopy under combined sciatic and femoral nerve block. They showed prolonged duration of anesthesia and of analgesia.

As regard VAS and total amount of morphine (mg) needed for each patient who required rescue analgesia (VAS >4), there was significant increase in Group 1 regarding the amount of rescue analgesia of morphine needed. And VAS showed significant increase in Group I than in Group II.

In agreement with this study, Casati et al., [25] compared the sciatic and femoral block and unilateral spinal anesthesia, it has been reported that higher doses of post-operative analgesia were required in unilateral spinal anesthesia.

In agreement with this study, Cohen JM, et al., [26] studied the effect of the addition of a preoperative sciatic nerve block to a femoral nerve block on adult patients undergoing Anterior Cruciate Ligament Reconstruction and found that additional of pre-operative sciatic nerve block $(20-30 \mathrm{~mL}$ ropivacaine $0.5 \%$ or bupivacaine $0.375 \%$ ) to a femoral nerve block $(20-30 \mathrm{~mL}$ ropivacaine $0.5 \%$ or bupivacaine $0.375 \%$ ) results in decreasing the VAS post-operative pain and need for rescue analgesics.

The complications associated with this block are local anesthetic toxicity, neuraxial block due 
to proximal spread, neurological complication which can be related to a PNB include needle trauma, intraneuronal injection and neuronal ischemia. Infectious complications like cellulitis, neuritis, skin infection around the injection site are more associated with continuous nerve block techniques rather than a single injection technique.

In this study, Paresthesia developed in four patients in Group II, while one patient developed paresthesia in Group I. There was higher number of patient developed paresthesia in Group II, headache developed in one patient in Group I, while no patient developed headache in Group II , PONV developed in two patients in Group I, while only one patient developed PONV in Group II, intravascular injection not developed in any patient in both group.

In agreement with this study M. Alipour, et al., [14] headache after spinal anesthesia was reported in two and eight patients in the unilateral and bilateral groups respectively.

Also Zaric et al., reported that incidence of side effects was very low in the PNB group compared to the epidural group; Singelyn et al., observed that continuous 3-in-1 block induces nearly 4 times fewer side effects than epidural analgesia; Fowler et al., reported that PNB may provide effective unilateral analgesia with lower incidence of opioid related and autonomic side effects and fewer serious neurological complication compared with epidural analgesia; Raj Kumar et al., also found no complication intraoperative or post-operative.

In contrast with this study, Imbelloni LE, et al., [27] who studied adults patients for major orthopedic surgery of the lower limbs under uni lateral spinal anesthesia reported that incidence of PDPH was $1.7 \%$, which was in agreement with the rate of $1.6 \%$ in Holmstriöm B, et al., [28] study. This could be explained by the addition of $0.2 \mathrm{mg}$ morphine to $3.5-4 \mathrm{ml}$ of bupivacaine $0.5 \%$ intrathecally.

In regional anesthesia, nausea and vomiting can occur due to different factors. The most important reason is that cerebral blood flow decreases in consequence of hypotension (hypotension is the most common complication in the spinal anesthesia. Other reasons are related to the level where block reaches. It may as well occur because of an increase in the block level, or because of the fact that structures related to peritonea stretch during the operation due to an inadequate block level or due to morphine consumption.
In agreement with the present study Kim JH, et al., [29], compared between femoral/sciatic nerve block with lateral femoral cutaneous nerve block and unilateral spinal anesthesia for total knee replacement arthroplasty, patients received $1.3 \mathrm{ml}$ of $0.5 \%$ hyperbaric bupivacaine intrathecally and $20 \mathrm{ml}$ of $1.5 \%$ mepivacaine for femoral and sciatic nerve block and $5 \mathrm{ml}$ of $1.5 \%$ mepivacaine for the lateral femoral cutaneous. They concluded that there was no difference in frequency of complications, the incidences of dizziness and postoperative nausea/vomiting, the rate of satisfaction with the surgical anesthesia and the post-operative analgesia, VAS scores during the post-operative period, and duration of IV PCA use between the two groups. This may be related to different injection substances.

Since the side effects and complications related with the anesthesia method affect the hospitalization duration of patients, anesthesia methods and anesthetic agents are very important.

\section{Conclusion:}

Both ULSA with $2 \mathrm{ml}$ heavy bupivacaine $0.5 \%$ given slowly over one minute and US guided FSNB using combination of $0.25 \%$ bupivacaine and $1 \%$ lidocaine resulted in comparable adequate intraoperative anesthesia with stable hemodynamics and adequate surgeon and patient satisfaction with minimal side effects. US guided FSNB was superior to ULSA in post-operative analgesia (longer time to first rescue analgesia, lower VAS score and smaller amount of rescue analgesia).

\section{Conflicts of interest: Nil.}

Authors' contributions: All authors had equal role.

\section{References}

1- SPASIANO A., FLORE I., PESAMOSCA A. and DELLA G.R.: Comparison between spinal anaesthesia and sciaticfemoral block for arthroscopic knee surgery. Minerva Anestesiologica, 73: 13-21, 2007.

2- MONTES F.R., ZARATE E., GRUESO R., GIRALDO J.C., VENEGAS M.P., GOMEZ A., et al.: Comparison of spinal anesthesia with combined sciatic-femoral nerve block for outpatient knee arthroscopy. Journal of Clinical Anesthesia, 20: 415-20, 2008.

3- ESMAOGLU A., KARAOGLU S., MIZRAK A. and BOYACI A.: Bilateral vs. unilateral spinal anesthesia for outpatient knee arthroscopies. Knee Surgery, Sports Traumatology, Arthroscopy, 12: 155-8, 2004.

4- FANELli G., CASATI D.A., ALDEGHERI G., BECCARIA P., BERTI M. and LEONI A.: Cardiovascular effects of two different regional anaesthetic techniques 
for unilateral leg surgery. Acta. Anaesthesiologica Scandinavica, 42: 80-4, 1998.

5- TEKYE S.M.M. and ALIPOUR M.: Comparison of the effects and complications of unilateral spinal anesthesia versus standard spinal anesthesia in lower-limb orthopedic surgery. Brazilian Journal of Anesthesiology, 64: 173-6, 2014.

6- GREEN L. and MACHIN S.J.: Managing anticoagulated patients during neuraxial anaesthesia. British Journal of Haematology, 149: 195-208, 2010.

7- HOWELL S., SEAR Y., YEATES D., GOLDACRE M., SEAR J. and FOEX P.: Risk factors for cardiovascular death after elective surgery under general anaesthesia. British Journal of Anaesthesia, 80: 14-9, 1998.

8- ROSARIO D., JACOB S., LUNTLEY J., SKINNER P and RAFTERY A.: Mechanism of femoral nerve palsy complicating percutaneous ilioinguinal field block. British Journal of Anaesthesia, 78: 314-6, 1997.

9- MARHOFER P., SCHRÖGENDORFER K., WALLNER T., KOINIG H., MAYER N. and KAPRAL S.: Ultrasonographic guidance reduces the amount of local anesthetic for 3-in-1 blocks. Regional Anesthesia and Pain Medicine, 23: 584-8, 1998.

10- BROMAGE P.R.: A comparison of the hydrochloride and carbon dioxide salts of lidocaine and prilocaine in epidural analgesia. Acta Anaesthesiologica Scandinavica, 9: 5569, 1965.

11- JENSEN M.P., KAROLY P. and BRAVER S.: The Measurement of Clinical Pain Intensity: A Comparison of Six Methods. Pain, 27: 117-26, 1986.

12- TALLUR K.P., SANIKOP C.S. and DHORIGOL M.G.: Anesthetic management of post-coronary artery bypass grafting patient posted for below-knee amputation. Journal of the Scientific Society, 43: 89, 2016.

13- IMBELLONI L.E., BEATO L. and CORDEIRO J.A.: Unilateral spinal anesthesia with low $0.5 \%$ hyperbaric bupivacaine dose. Revista Brasileira de Anestesiologia, 54: 700-6, 2004.

14- TEKYE S.M.M. and ALIPOUR M.: Comparison of the effects and complications of unilateral spinal anesthesia versus standard spinal anesthesia in lower-limb orthopedic surgery. Revista Brasileira de Anestesiologia, 64: 173-6, 2014.

15- TUMMALA V., RAO L.N., VALLURY M.K. and SANAPALA A.: A comparative study-efficacy and safety of combined spinal epidural anesthesia versus spinal anesthesia in high-risk geriatric patients for surgeries around the hip joint. Anesthesia, Essays and Researches, 9: 185, 2015.

16- CHOHAN U., AFSHAN G., HODA M. and MAHMUD S.: Haemodynamic effects of unilateral spinal anesthesia in high risk patients. JPMA The Journal of the Pakistan Medical Association, 52: 66-9, 2002.

17- GLASER C., MARHOFER P., ZIMPFER G., HEINZ M.T., SITZWOHL C., KAPRAL S., et al.: Levobupivacaine versus racemic bupivacaine for spinal anesthesia. Anesthesia \& Analgesia, 94: 194-8, 2002.
18- AKKAYA A., TEKELIOGLU U.Y., DEMIRHAN A., OZTURAN K.E., BAYIR H., KOCOGLU H., et al.: Ultrasound-guided femoral and sciatic nerve blocks combined with sedoanalgesia versus spinal anesthesia in total knee arthroplasty. Korean Journal of Anesthesiology, 67: 90-5, 2014.

19- TANTRY T.P., KADAM D., SHETTY P. and BHANDARY S.: Combined femoral and sciatic nerve blocks for lower limb anaesthesia in anticoagulated patients with severe cardiac valvular lesions. Indian Journal of Anaesthesia, 54: 235-9, 2010.

20- FANELLI G., BORGHI B., CASATI A., BERTINI L., MONTEBUGNOLI M. and TORRI G.: Unilateral bupivacaine spinal anesthesia for outpatient knee arthroscopy. Canadian Journal of Anesthesia, 47: 746-51, 2000.

21- VALANNE J.V., KORHONEN A.M., JOKELA R.M., RAVASKA P. and KORTTILA K.K.: Selective spinal anesthesia: A comparison of hyperbaric bupivacaine 4 $\mathrm{mg}$ versus $6 \mathrm{mg}$ for outpatient knee arthroscopy. Anesthesia \& Analgesia, 93: 1377-9, 2001.

22- CHAKRAVARTHY V., ARYA V.K., DHILLON M.S and CHARI P.: Comparison of regional nerve block to epidural anaesthesia in day care arthroscopic surgery of the knee. Acta. Orthop. Belg., 70: 551-9, 2004.

23- FOURNIER R., VAN GESSEL E., GAGGERO G., BOCCOVI S., FORSTER A. and GAMULIN Z.: Post-operative analgesia with "3-in-1" femoral nerve block after prosthetic hip surgery. Canadian Journal of Anaesthesia, 45: 34, 1998.

24- SANSONE V., De PONTI A., FANELLI G. and AGOSTONI M.: Combined sciatic and femoral nerve block for knee arthroscopy: 4 years' experience. Archives of Orthopaedic and Trauma Surgery, 119: 163-7, 1999.

25- CASATI A., CAPPELLERI G. FANELLI G., BORGHI B., ANELATI D., BERTI M., et al.: Regional anaesthesia for outpatient knee arthroscopy: A randomized clinical comparison of two different anaesthetic techniques. Acta. Anaesthesiologica Scandinavica, 44: 543-7, 2000.

26- COHEN J., KOLODZIE K., SHAH S. and ALESHI P.: Pre-operative sciatic and femoral nerve blocks for anterior cruciate ligament reconstruction: A retrospective analysis. J. Anesth. Clin. Res., 5: 2, 2014.

27- IMBELLONI L.E. and BEATO L.: Comparison between spinal, combined spinal-epidural and continuous spina anesthesias for hip surgeries in elderly patients: A retrospective study. Brazilian Journal of Anesthesiology, 52: 316-25, 2002

28- HOLMSTRÖM B., LAUGALAND K., RAWAL N. and HALLBERG S.: Combined spinal epidural block versus spinal and epidural block for orthopaedic surgery. Canadian Journal of Anaesthesia, 40: 601-6, 1993.

29- KIM J.H., CHO M.R., KIM S.O. KIM J.E., LEE D.K and ROH W.S.: A comparison of femoral/sciatic nerve block with lateral femoral cutaneous nerve block and combined spinal epidural anesthesia for total knee replacement arthroplasty. Korean Journal of Anesthesiology, 62: 448-53, 2012. 


\section{دراسة مقارنة بين التخدير النصفى آحادى الجانب وإستخدام الموجات الصوتية

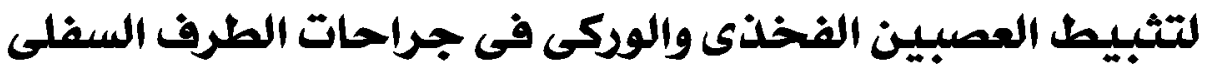

المقدمة: تستخدم تقنيات التخدير الموضعى كبديل للتخدير العام لآنها توفر التخدير الكافى آثناء الجراحة كما توفر وقتاً أطول للتسكين

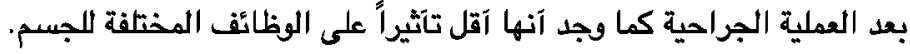

الهدف من البحث: يهدف هذا البحث إلى المقارنة بين التخدير النصفى آحادى الجانب وبين إستخدام الموجات الصوتية لتبيط العصبين الفخذى والوكى فى حالات جراحات الطرف السفلى.

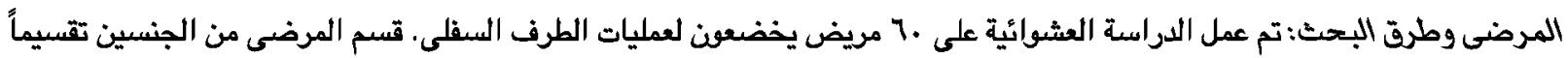

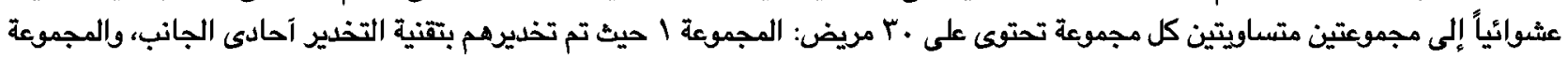

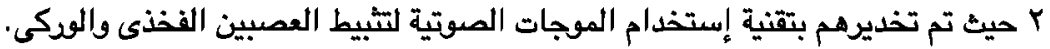

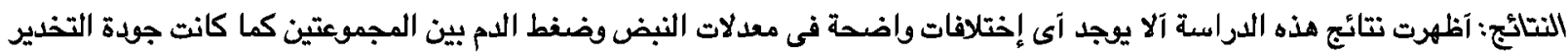

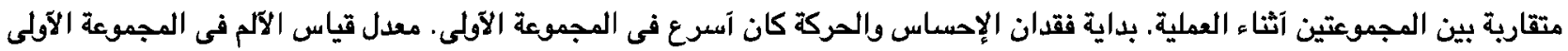

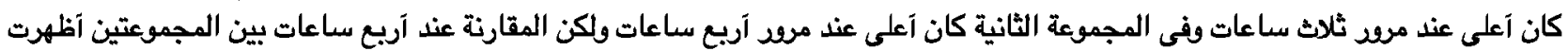

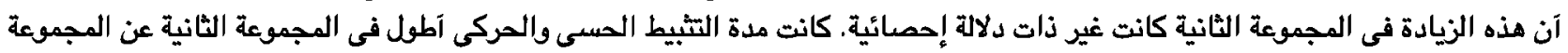

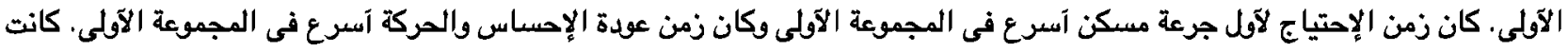

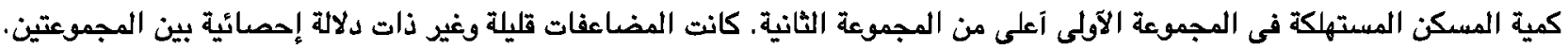
كان مستوى إرضاء المرضى والجراحين عالياً ومتقارباً في المجمئ الهمعتين.

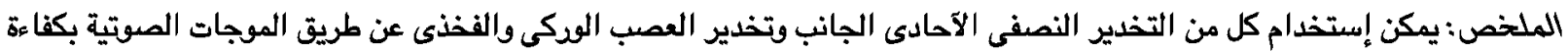

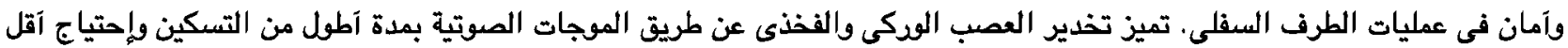
لإستخدام مزيلات الآلم. 